Article

\title{
On the Nature of Voltammetric Signals Originating from Hydrogen Electrosorption into Palladium-Noble Metal Alloys
}

\author{
Mariusz Lukaszewski, Katarzyna Hubkowska, Urszula Koss and Andrzej Czerwiński * \\ Department of Chemistry, Warsaw University, Pasteura 1, Warsaw 02-093, Poland; \\ E-Mails: maluk@chem.uw.edu.pl (M.Ł.); khubkowska@chem.uw.edu.pl (K.H.); \\ ukoss@chem.uw.edu.pl (U.K)
}

* Author to whom correspondence should be addressed; E-Mail: aczerw @ chem.uw.edu.pl;

Tel.: +48-22-822-0211; Fax: +48-22-822-5996.

Received: 28 August 2013; in revised form: 8 October 2013 / Accepted: 12 October 2013 /

Published: 22 October 2013

\begin{abstract}
Hydrogen sorption/desorption signals observed on cyclic voltammograms in experiments on hydrogen electrosorption into Pd-noble metal alloys (Pd-Au, Pd-Pt, Pd-Rh, $\mathrm{Pd}-\mathrm{Ru}, \mathrm{Pd}-\mathrm{Pt}-\mathrm{Rh}, \mathrm{Pd}-\mathrm{Pt}-\mathrm{Au})$ were characterized. The influence of electrosorption potential, scan rate and alloy bulk composition on the features of the hydrogen peaks was investigated. The experimental results were compared with those obtained on the basis of a model taken from the literature. It was confirmed that the rate of the $\alpha-\beta$ phase transition controls the overall rate of the process of hydrogen absorption/desorption into/from thin Pd-based electrodes. It was demonstrated that from the analysis of the changes of the hydrogen oxidation peak potential with the hydrogen electrosorption potential in cyclic voltammetric experiments it is possible to determine the limiting Pd bulk content, below which the $\beta$-phase in the alloy-hydrogen system is not formed.
\end{abstract}

Keywords: palladium alloys; limited volume electrodes; hydrogen adsorption and absorption; cyclic voltammetry; phase transition

\section{Introduction}

Electrochemical adsorption and absorption of hydrogen on/in metals or alloys are important reactions in electrocatalysis, for chemical power sources (fuel cells, batteries, supercapacitors) and in 
the context of hydrogen storage [1-6]. These processes are also of a fundamental significance for the understanding hydrogen interactions with solid materials [7-11].

Platinum group metals are widely used in electrochemical studies on hydrogen adsorption and evolution due to their great affinity for hydrogen, which can be reversibly adsorbed already at potentials positive to the hydrogen evolution potential (so-called $\mathrm{H}$ underpotential deposition phenomenon) and further at potentials in the hydrogen evolution region ( $\mathrm{H}$ overpotential deposition) [12,13]. Among platinum metals palladium plays a special role as the only noble metal that under normal conditions does not only adsorb but also absorbs hydrogen [7,14]. The palladium-hydrogen system has a long research history and is treated as a model system for other hydrogen-absorbing materials. Since the high ability for hydrogen sorption is retained in most Pd-rich alloys, these systems provide a unique opportunity to study the effect of other metals addition on hydrogen sorption properties $[7-10,15,16]$. Beside the importance in fundamental studies, these results can be helpful for the application of $\mathrm{Pd}$ alloys as elements of various equipments where hydrogen absorption takes place (e.g., membranes, electrodes, catalysts). By investigation of the influence of Pd alloying with other metals on the alloy's absorption properties we might be able to understand better the complex reactions taking place in multi-component alloys designed for hydrogen storage or used as electrode materials in electrochemical power sources.

The process of hydrogen electrosorption in $\mathrm{Pd}$ is a rather complex reaction that consists of several steps involving various forms and phases of hydrogen adsorbed on the surface and absorbed in the bulk of the electrode [13,17-19]. The complexity is even greater in the case of Pd alloys, where the properties of the alloying metal are superimposed with those of pure Pd. Therefore, in electrochemical experiments it is often difficult to separate contributions from different forms of hydrogen participating in the total measured response. For instance, on cyclic voltammograms recorded for Pd-Pt alloys one can observe multiple peaks originating from different forms of adsorbed hydrogen (weakly and strongly adsorbed hydrogen on both $\mathrm{Pt}$ and $\mathrm{Pd}$ surface atoms) and different phases of absorbed hydrogen ( $\alpha$ - and $\beta$-phase) [20].

In the literature several methods have been proposed to distinguish between hydrogen adsorption and absorption on/in Pd electrodes. The early methods of extracting the contribution from hydrogen adsorption were based on the fact that adsorption is much faster than absorption. Thus, by extrapolating the measured hydrogen charge to zero time of an experiment (e.g., to infinite charging rate with the galvanostatic method or infinite scan rate in cyclic voltammetry) it could be possible to determine the amount of adsorbed hydrogen [21].

The second approach relies on the effect of electrode thickness on the relative contributions from adsorption and absorption [22-24]. This method requires the preparation of a series of electrodes with different thicknesses and the extrapolation of the results to zero thickness in order to extract the contribution from adsorption alone. However, that procedure does not take into account the effect of the thickness itself on the properties of various forms of sorbed hydrogen, since it assumes that the changes in thickness alter only the proportions between the amount of adsorbed and absorbed hydrogen without the effect of that parameter on the H/Pd ratio, surface coverage, number of phases, etc. These effects are even more important in the case of thin films of Pd alloys when different thickness may additionally affect the alloy bulk structure and phase arrangement, as well as the properties of the surface. 
Another method for the identification of electrode processes with the participation of adsorbed and absorbed hydrogen is based on a different influence of various adsorbates on hydrogen adsorption and absorption. It was observed that crystal violet [18,23,25-28], benzotriazole [29] or carbon dioxide [30,31] as well as some underpotentially deposited metals [26,28,32], when adsorbed on the surface of Pd or Pd alloys, selectively block hydrogen adsorption without a significant effect on hydrogen absorption. Therefore, in the presence of those adsorbates hydrogen adsorption currents are at least partially suppressed, while absorption currents are undisturbed or even increased. However, this approach does not allow distinguishing between different phases of absorbed hydrogen and requires electrode poisoning, which in some cases should be avoided. Moreover, in the case of alloys the presence of the adsorbate may irreversibly alter the alloy surface composition and phase arrangement.

In a series of our papers [24,30,31] we have applied the above two methods to characterize hydrogen adsorption and absorption processes on/in $\mathrm{Pd}$ and its alloys with $\mathrm{Au}, \mathrm{Pt}$ and $\mathrm{Rh}$. In the present report we analyze various hydrogen-related signals observed in electrochemical experiments relying on cyclic voltammmetric data obtained during standard procedures applied for the characterization of hydrogen absorption properties of Pd alloys. We demonstrate a good qualitative agreement between the effect of alloy bulk composition on $\mathrm{CV}$ response and the trends predicted on the basis of the model developed by Zhang et al. [33] for thin Pd-based layers, where the role of the $\alpha-\beta$ phase transition in the process of hydrogen absorption/desorption was taken into account. We show that with a careful treatment of the electrochemical results it is possible to determine the influence of alloy bulk composition on the width of the two-phase region in the alloy-hydrogen system.

\section{Results and Discussion}

Figure 1 shows cyclic voltammograms recorded in the potential region of hydrogen electrosorption on/in a Pd multi-component alloy for various lower potential limits. At each lower potential limit the electrode was polarized for a period sufficient to obtain its steady state saturation with hydrogen (as determined in separate chronoamperometric experiments). After complete saturation, the anodic scan was recorded until all hydrogen was oxidized, followed next by a cathodic scan. The plot below CV curves presents the influence of electrosorption potential on the amount of electrosorbed hydrogen (expressed as the hydrogen-to-metal atomic ratio, $\mathrm{H} / \mathrm{M}$ ) determined by the integration of the oxidation currents on CVs.

As reported earlier [20,34], two main groups of signals can be distinguished on CV curves in hydrogen electrosorption experiments performed with Pd-based electrodes. When hydrogen electrosorption potential is relatively high, a pair of small waves is observed in the range $0.23-0.32 \mathrm{~V}$ (signal 1 in Figure 1). These signals are more pronounced for some alloys than for pure Pd. For low electrosorption potential the pair of larger peaks appears below $0.15 \mathrm{~V}$ (signal 2). The position and height of the former signals is only weakly dependent on electrosorption potential, while the current and potential of the latter anodic peaks are strongly influenced by electrosorption potential. The separation between anodic and cathodic peaks for signal 1 is small (it does not exceed $20 \mathrm{mV}$ ), as compared with a much greater potential difference observed for anodic and cathodic peaks for signal 2. The features of both types of hydrogen signals are summarized in Table 1 (see further text for details). 
Figure 1. Cyclic voltammograms recorded in the potential region of hydrogen electrosorption in a $88.9 \% \mathrm{Pd}-3.4 \% \mathrm{Pt}-7.7 \%$ Au alloy for various lower potential limits (scan rate $0.01 \mathrm{~V} \mathrm{~s}^{-1}$, temperature $298 \mathrm{~K}$ ) together with a the hydrogen-to-metal atomic ratio $(\mathrm{H} / \mathrm{M})$ vs. potential dependence obtained from hydrogen oxidation charges after integration of anodic voltammetric currents.
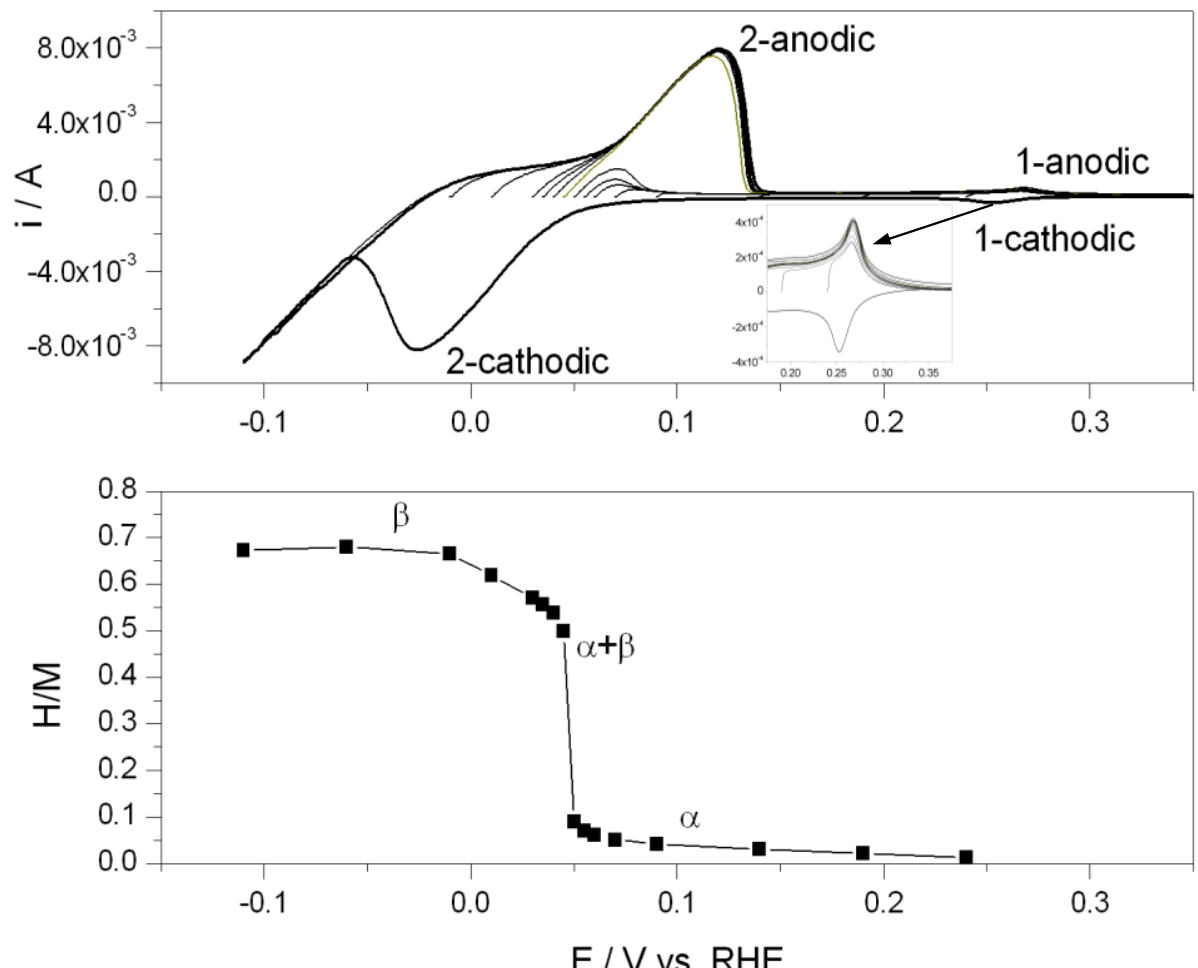

Table 1. Features of two groups of $\mathrm{CV}$ signals related to hydrogen sorption/desorption into/from $\mathrm{Pd}$ and Pd-rich alloys in $0.5 \mathrm{M} \mathrm{H}_{2} \mathrm{SO}_{4}$ at $298 \mathrm{~K}$.

\section{Group of hydrogen electrosorption signals}
(a) above $0.23 \mathrm{~V}$;
(a) below $0.15 \mathrm{~V}$;
(b) weak effect of sorption potential;
(b) strong effect of sorption potential;
(c) small potential difference between anodic
(c) great potential difference between anodic and

Peak and cathodic signal, almost constant with alloy cathodic signal, strongly dependent on alloy bulk potential bulk composition; composition;

(d) slight effect of scan rate;

(d) strong effect of scan rate;

(e) anodic peak position almost constant with decreasing Pd bulk content in alloy

(e) anodic peak shifted negatively with decreasing

Pd bulk content in alloy

(f) high maximum, well-defined peak;

Peak

(f) small maximum, often purely defined peak;

current

(g) weak effect of sorption potential;

(g) strong effect of sorption potential;

(h) proportional to $\mathrm{v}^{0.9-1}$

(h) proportional to $\mathrm{v}^{0.55-0.75}$ for sorption potentials below phase transition and to $\mathrm{v}^{0.75-0.9}$ above phase transition

The influence of electrode potential on the amount of absorbed hydrogen was described in detail in numerous papers. On H/M vs. potential plots for Pd-rich electrodes one can distinguish the regions 
where absorbed hydrogen exists in the form of the $\alpha$ - or $\beta$-phase, and an intermediate region of the phase transition. Since all the electrodes studied also adsorb hydrogen, the H/M ratio contains the contribution from adsorbed hydrogen. However, our electrodes are neither extremely thin nor rough, with a thickness corresponding to several thousands of atomic layers and the roughness factor not exceeding 300, therefore adsorbed hydrogen does not modify significantly the value of H/M ratio.

The comparison of the potential ranges of the above current signals with the course of H/M vs. potential plot reveals that signal 1 is placed entirely in the region corresponding to the existence of the $\alpha$-phase of absorbed hydrogen. Signal 2 already appears after electrosorption performed in the $\alpha$-phase region but rapidly grows only after the $\alpha-\beta$ phase transition. As concluded earlier by Grden et al. [20], hydrogen absorption in the $\alpha$-phase contributes to both signals, while absorption in the $\beta$-phase is related only to the second signal. Since hydrogen adsorption is possible in the whole potential range where hydrogen absorption takes place, the former process contributes to both signals. To verify these hypotheses the analyses of various features of the hydrogen signals were carried out.

Figure 2 shows the influence of scan rate on anodic peak currents recorded during the voltammetric oxidation of electrosorbed hydrogen in Pd and Pd alloys. It can be seen that in double-logarithmic coordinates the points for both signals follow straight lines, however, with different slopes for each signal. The analysis of various samples has revealed that peak 1 currents are proportional to scan rate of the power of $0.9-1$, while for peak 2 the exponent is lower, i.e., ca. 0.55-0.75. Such a difference suggests different electrochemical nature of the processes that contribute to each signal. These results may indicate that peak 1 originates mainly from a surface reaction, i.e., the oxidation of adsorbed hydrogen. The origin of peak 2 seems to be more complex, as its current is proportional to scan rate of the power between 0.5 and 1 . The former value is typical for a diffusion controlled processes in a semi-infinite diffusion field and since hydrogen absorption involves diffusion within the electrode bulk, at first glance the result obtained could suggest hydrogen absorption as the dominant process related to peak 2 .

Figure 2. Influence of scan rate on anodic peak currents of signals 1 and 2 recorded during voltammetric oxidation of electrosorbed hydrogen in $\mathrm{Pd}$ and $\mathrm{Pd}$ alloys (in double-logarithmic coordinates, slopes indicated at the left). Temperature $298 \mathrm{~K}$.

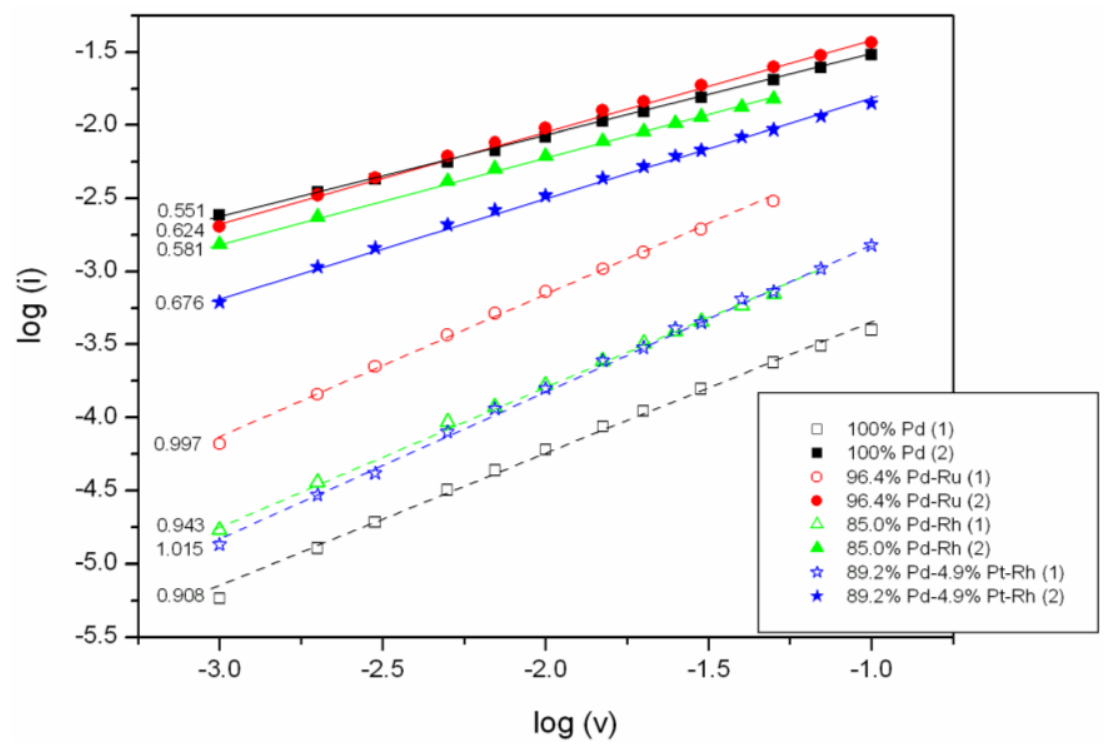


A similar dependence of different hydrogen peak currents on scan rate was obtained by Guerin and Attard [35] for nanostructured (particle diameter $2.5 \mathrm{~nm}$ ) Pd-Pt layers (62\% Pd). They distinguished two groups of peaks, with different courses of current $v s$. scan rate dependence. The height of peaks placed at higher potentials [between -0.1 and $+0.1 \mathrm{~V}$ vs. SCE (saturated calomel electrode)] was proportional to scan rate with the exponent close to unity in the range of scan rate between 1 and 1000 $\mathrm{mV} / \mathrm{s}$, while for peaks placed at lower potentials ( $c a .-0.2 \mathrm{~V} v \mathrm{~s}$. SCE) the exponent changed from 0.90 to 0.63 with increasing scan rate. According to the authors, such a behavior confirmed the contribution from a diffusional process in the latter case.

However, for diffusion-controlled processes occurring in thin layer electrodes (i.e., with a limited diffusion field) peak current proportionality to scan rate of the power of 1 is expected. The fact that the exponent in the case of signal 2 is distinctly lower than unity indicates that the above condition is not fulfilled.

According to a model developed by Zhang et al. [33] for CV responses during electrochemical hydrogen insertion/removal into/from thin Pd layers, it is not diffusion but the rate of the $\alpha-\beta / \beta-\alpha$ phase transitions which determines the magnitude of hydrogen absorption/desorption current. In the above model anodic and cathodic peak currents in the region of signal 2 are a function of the following parameters:

1. exchange current density of the Volmer reaction;

2. surface coverage with adsorbed hydrogen;

3. maximum number of sites in the electrode volume available for absorbed hydrogen;

4. difference in limiting hydrogen concentrations in the $\alpha$ - and $\beta$-phases;

5. electrode thickness;

6. electrode roughness factor;

7. scan rate;

8. temperature.

The model enables the prediction of the dependence of peak current on scan rate during hydrogen oxidation in a CV experiment for a given electrode constitution, thickness roughness factor and temperature. For our electrodes characterized by thickness between 0.7 and $1.1 \mu \mathrm{m}$ and roughness factor in the range 20-300, the calculated (on the basis of Equation 11 in [33]) exponent values are between $c a$. 0.50 and 0.65 , i.e., similar to those observed in our experiments. Moreover, the trends in the differences in the exponent values for Pd and various alloys are consistent with the changes in hydrogen absorption properties (for alloys the difference in limiting hydrogen concentration in both phases decreases) and electrode roughness (our alloy electrodes were usually rougher than pure Pd).

The small positive deviations from the theoretical values can be explained assuming that signal 2 is due to a mixed phase transition controlled process (absorption) and surface process (adsorption). This conclusion is consistent with the mechanism of hydrogen absorption that involves adsorption as an intermediate step, together with diffusion of hydrogen to the bulk and phase transition between the phases of absorbed hydrogen. It should be added that when peak 2 current was recorded for sorption potential just above the phase transition potential, the slope of $\log \mathrm{I} v s . \log \mathrm{v}$ plot was higher than the values for sorption potential in the $\beta$-phase region, exceeding 0.90 when sorption potential approached the region of peak 1 . This observation can be explained by the facts that at higher sorption potential the 
phase transition does not occur and also the contribution from hydrogen adsorption becomes more significant.

In Figure 3 the influence of alloy bulk composition on the slope of $\log \mathrm{I} v s . \log \mathrm{v}$ plot is shown. It is demonstrated that the slope for peak 1 weakly depends on the bulk composition of the Pd-Ru alloys. It means that in the composition range studied the electrochemical nature of that signal remains practically constant. On the other hand, for peak 2 the slope is higher for alloys containing less $\mathrm{Pd}$ in the bulk, which suggests a greater contribution from the surface process for alloys with smaller Pd content. This is probably due to the fact that addition of a greater amount of Ru decreases the alloy absorption capacity, and therefore the contribution from the bulk process to signal 2 is smaller.

Figure 3. Influence of bulk composition of Pd-Ru alloys on the slope of log I vs. $\log \mathrm{v}$ plot for signals 1 and 2. Temperature $298 \mathrm{~K}$.

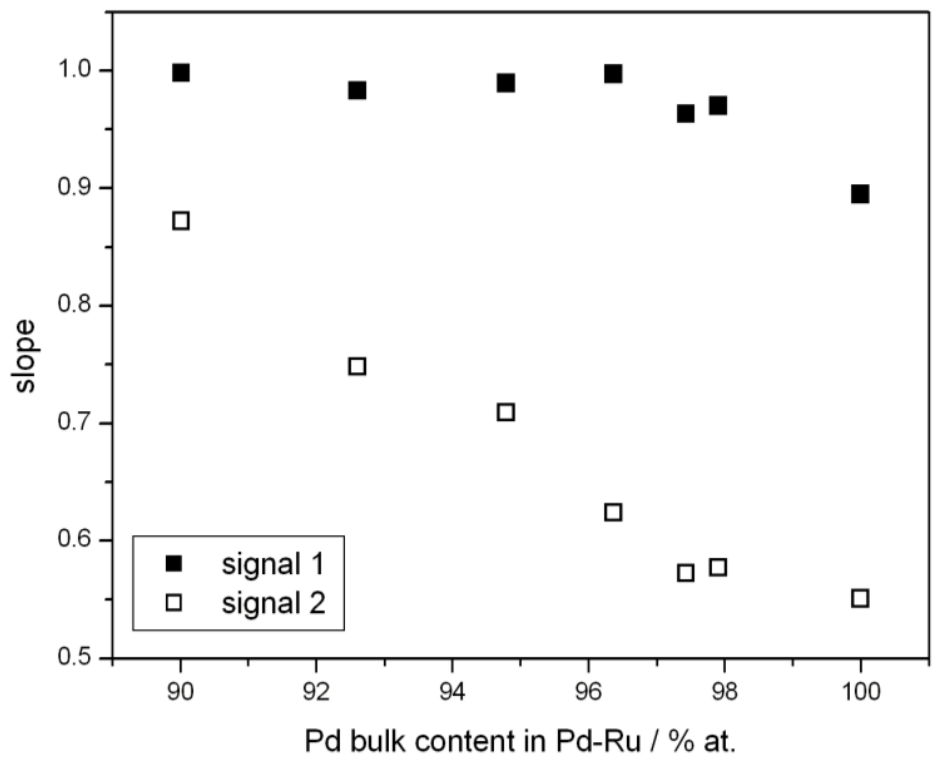

Figure 4 shows the influence of alloy bulk composition on anodic and cathodic peak potentials of signal 2 for two electrosorption potentials, i.e., $0.07 \mathrm{~V}$ and $-0.11 \mathrm{~V}$. In the case of electrosorption at $0.07 \mathrm{~V}$ the $\beta$-phase of absorbed hydrogen cannot be formed, since for all alloys this potential is higher than the value required for the phase transition. Thus, under these conditions hydrogen is adsorbed on the surface and absorbed in the $\alpha$-phase only. Figure 4 indicates that in this case hydrogen oxidation peak 2 is weakly dependent on alloy composition, slightly increasing with decreasing Pd content in $\mathrm{Pd}-\mathrm{Au}$ alloys or remaining almost constant for Pd-Pt, Pd-Rh and Pd-Ru alloys.

According to the literature $[7,36]$, the limiting hydrogen content in the $\alpha$-phase slowly rises with the amount of the alloying metal. However, since the phase transition potential for Pd-Au alloys is shifted positively, for a given potential in the $\alpha$-phase region the amount of electrosorbed hydrogen in $\mathrm{Pd}-\mathrm{Au}$ alloys is higher than in Pd-Pt or Pd-Rh, where the phase transition potential is shifted negatively. This behavior, resulting from the changes in the crystal lattice dimensions [7,37,38] and electronic structure [7,39] upon alloy formation, could be responsible for the different tendencies of changes in peak position for various alloys. Nevertheless, the amount of hydrogen absorbed in the $\alpha$-phase (as well as the coverage with hydrogen adsorbed in that potential range) in all Pd-rich alloys is small (H/M ratio below 0.1 ). In fact, the $\alpha$-phase can be treated as an ideal dilute solid solution of hydrogen in the 
metal and the relative increase in crystal lattice dimensions during the $\alpha$-phase formation does not exceed $0.13 \%$ (as compared to more than $3 \%$ for the $\beta$-phase formation) [37,38]. Therefore, alloy bulk composition has a weak effect on peak potential of signal 2 when hydrogen is absorbed in the $\alpha$-phase only.

Figure 4. Influence of alloy bulk composition on potentials of voltammetric peaks due to hydrogen sorption and desorption. Temperature 298 K. (a) Pd-Pt alloys; (b) Pd-Au alloys; (c) Pd-Rh alloys; (d) Pd-Ru alloys; ( $\mathbf{a})$ anodic signal 1, sorption at $-0.11 \mathrm{~V}$; ( $\square$ ) cathodic signal $1 ;(\bullet)$ anodic signal 2 , sorption at $-0.11 \mathrm{~V} ;(\circ)$ cathodic signal $2 ;(*)$ anodic signal 2 , sorption at $0.07 \mathrm{~V}$.
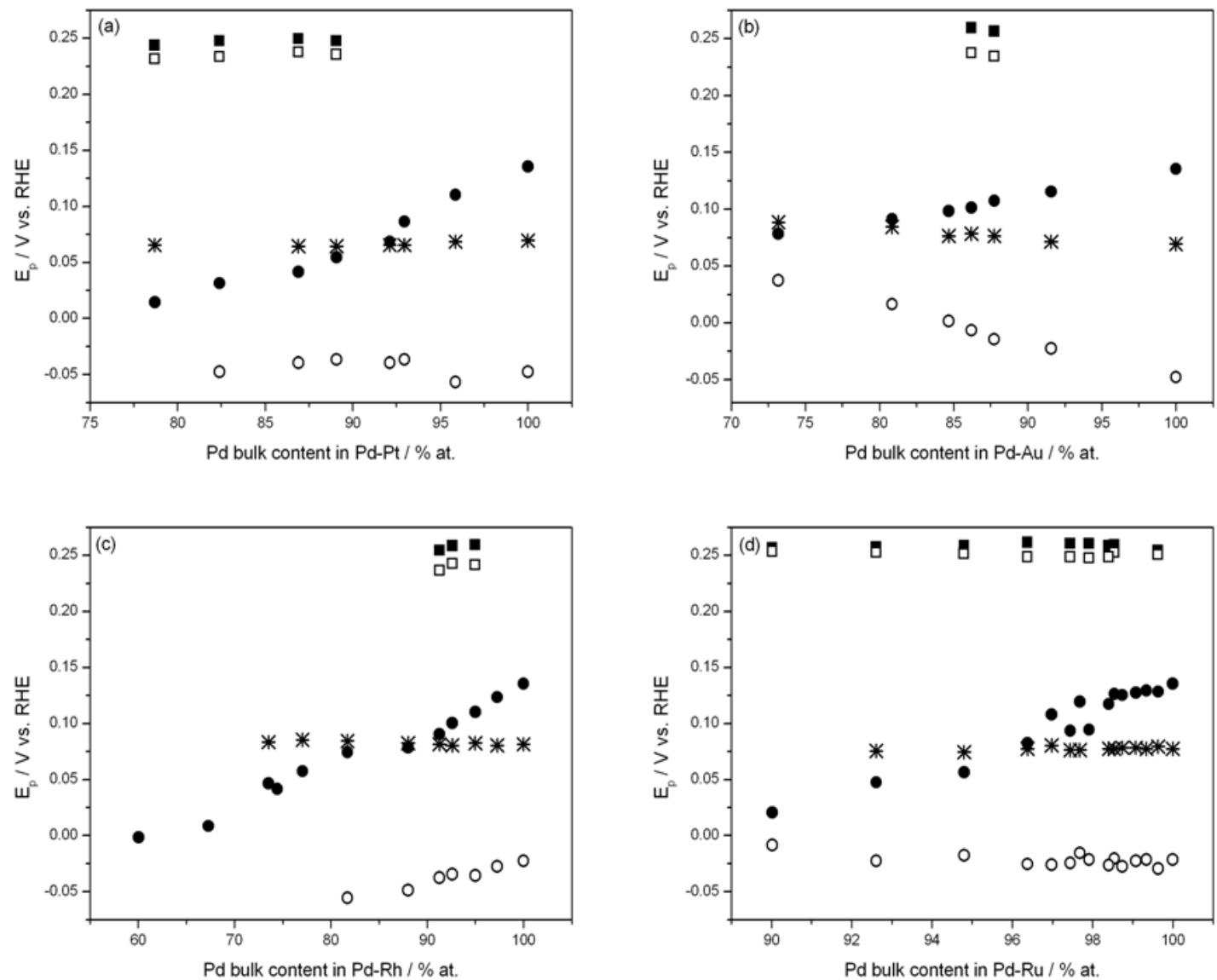

For the lower electrosorption potential there is a possibility of $\beta$-phase formation provided that the alloy is rich enough in $\mathrm{Pd}$. Under these conditions alloy composition strongly affects the position of hydrogen peaks of signal 2. Figure 4 demonstrates that for all alloys studied the potential of the anodic peak gradually decreases with the additive of the second metal, while the trend of the changes in the position of the cathodic peak varies for different alloys.

The strong effect of alloy bulk composition on peak potentials of signal 2 when hydrogen is absorbed at low potentials is related to the fact that the above situation is qualitatively different from that for the higher electrosorption potential. In the latter case after complete saturation with hydrogen absorbed in the $\alpha$-phase the hydrogen distribution inside the electrode is homogeneous and the system remains single-phase during the entire period of hydrogen extraction. On the other hand, in the former case one phase of absorbed hydrogen is present only during initial or final stages of hydrogen 
absorption/oxidation. When both phases coexist, the phase transition occurs with the phase boundary moving from the surface to the interior of the electrode or vice versa.

In Zhang's model [33] the difference between the potentials of anodic and cathodic peaks is a function of parameters 1-8 and, additionally, of the extent of absorption/desorption hysteresis. For a given temperature parameters 1-4 and hysteresis are dependent on the electrode bulk composition. Thus, on the basis of the above model it is possible to examine the influence of alloy composition on hydrogen absorption/desorption currents in CV experiments. In particular, parameters 1 and 4 may differ between various alloys of different Pd bulk content. For instance, the exchange current density at $298 \mathrm{~K}$ in $0.5 \mathrm{H}_{2} \mathrm{SO}_{4}$ on $\mathrm{Pd}$ and $\mathrm{Pt}$ is of the order of $1 \mathrm{~mA} / \mathrm{cm}^{2}$, for $\mathrm{Rh}$ it is $c a .0 .25 \mathrm{~mA} / \mathrm{cm}^{2}$, for Ru $c a$. $0.06 \mathrm{~mA} / \mathrm{cm}^{2}$, while for $\mathrm{Au}$ it is of the order of $0.001 \mathrm{~mA} / \mathrm{cm}^{2}$ [40]. However, for the alloys rich in $\mathrm{Pd}$ the differences in exchange current are expected to be smaller due to the predominant effect of Pd. A greater effect is expected from the changes in the difference in limiting hydrogen concentrations in both phases, which generally tends to markedly decrease with decreasing Pd bulk content, but for $\mathrm{Pd}$-rich Pd-Rh alloys this tendency is weaker than for Pd-Au and, especially, Pd-Pt alloys. The hysteresis also becomes smaller with decreasing Pd bulk content, however, each system is characterized by a different limiting composition where the hysteresis disappears [41]. More reversible hydrogen adsorption on the surface, a narrower two-phase region in the alloy-hydrogen system and smaller hysteresis make the phase transition, and thus the overall absorption/desorption process, faster.

Figure 5 presents the results of the calculations of the difference in anodic and cathodic peak potentials for signal 2 based on the equations derived by Zhang et al. \{Equations (4)-(6), (9), (10) in [33]\}. In order to examine the effect of alloy composition alone, for all calculations constant values of the roughness factor and thickness were taken as 50 and $1 \mu \mathrm{m}$, respectively, while the scan rate was equal to $0.01 \mathrm{~V} / \mathrm{s}$ and temperature $298 \mathrm{~K}$. Since there are few data on hydrogen adsorption on Pd alloys, the values of surface coverage with adsorbed hydrogen at phase boundaries were taken to be the same as those used by Zhang et al. [33] for Pd. This assumption seems reasonable as the adsorption properties of the alloys are more similar than the absorption properties. Other parameters were changed according to a given alloy composition on the basis of our earlier results.

Figure 5. Influence of alloy bulk composition on the difference in anodic and cathodic peak potentials for signal 2 (normalized to the values for pure Pd): (a) experimental values; (b) results of calculations based on the equations derived by Zhang et al. \{Equations (4)-(6), (9), (10) in [33]\}. Temperature $298 \mathrm{~K}$.
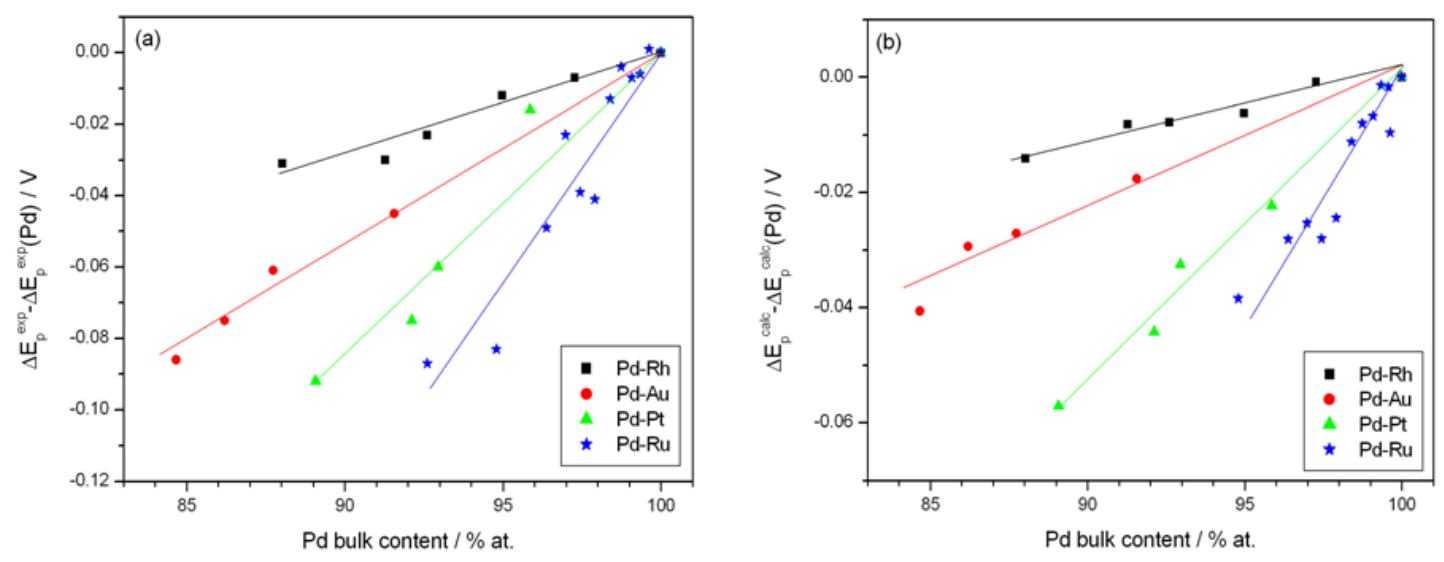
It can be seen in Figure 5 that although the exact values of peak potential difference calculated according to the model differ from the experimental values (where for real electrodes the thickness and roughness also varied), there is a good agreement in the trends of the changes in the potential difference with alloy bulk composition. The model reproduces the lowering in potential difference with decreasing $\mathrm{Pd}$ content with the qualitative differences between various alloys, namely the strongest effect of bulk composition in the case of $\mathrm{Pd}-\mathrm{Ru}$ alloys and the weakest effect in the case of $\mathrm{Pd}-\mathrm{Rh}$ alloys. Therefore, these results seem to confirm the important influence of the phase transition on the rate of the overall electrosorption process in thin Pd-based electrodes and are in line with the conclusions made in our earlier studies.

The experimental variation of the changes in cathodic peak potential with alloy bulk composition cannot be fully explained by the above model, in which anodic and cathodic currents are symmetrical with respect to the potential in the middle of the phase transition region, and therefore for all alloys a positive shift of cathodic signal with decreasing Pd content is predicted. It should be remembered, however, that the above model is simplified and hydrogen electrosorption in Pd-based electrodes is a quite complex process, where the phase transition is only one of several steps [42,43]. Nevertheless, a good agreement between theoretical calculations based on Zhang's model and earlier experiments with Pd thin films carried out by Czerwiński et al. [44] was demonstrated [33].

The negative shift of cathodic peak for $\mathrm{Pd}-\mathrm{Rh}$ alloys may be at least partially attributed to the lower thermodynamic stability of the $\beta$-phase, which means that the $\beta$-phase starts to be formed at lower potential. However, despite a similar effect of Pt additive on the thermodynamic parameters of the $\beta$-phase formation, cathodic peak potential is practically constant for various alloy compositions. It is possible in that case, that the facilitated kinetics of hydrogen adsorption on Pt plays a certain role, which weakens the unfavorable thermodynamic effect. In the case of Pd-Au the strong positive shift of cathodic peak potential probably results from higher stability of the $\beta$-phase [36,45]. For all alloys studied the reduction of both hysteresis and the miscibility gap in the alloy-hydrogen system lead to greater electrochemical reversibility between absorption and desorption processes as compared to pure Pd.

Since signal 2 is strongly affected by the process of the phase transition, one could expect that the way of its evolution with alloy composition reflects the changes in the properties of the phases of absorbed hydrogen in the system studied. In Figure 6 the potential of anodic peak 2 is plotted against the electrosorption potential for Pd alloys of various bulk compositions. It can be seen that for electrosorption potentials corresponding to the $\alpha$-phase existence only, the peak potential decreases with decreasing electrosorption potential, regardless of the electrode constitution. However, in the case of pure Pd and the alloys very rich in Pd an abrupt increase in peak potential is then observed with a narrow range of the electrosorption potential. This positive jump corresponds to the rapid increase in the peak height visible in Figure 1 and it can be related to the process of the $\alpha-\beta$ phase transition, i.e., the appearance of the hydrogen-rich $\beta$-phase when the electrosorption potential becomes low enough. Then the peak potential reaches an almost constant value in the region of the pure $\beta$-phase. On the other hand, for the alloys poor in $\mathrm{Pd}$, where a single phase of absorbed hydrogen is present in the alloy-hydrogen system, peak potential changes are monotonic until a plateau observed for the lowest electrosorption potential.

In contrast, the potential of anodic peak 1 is practically unchanged for all electrosorption potentials and for different alloy compositions. 
Figure 6. Influence of the electrosorption potential on the peak potential of anodic signals 1 and 2 for Pd alloys of various bulk compositions. Temperature 298 K. (a) Pd-Pt alloys; (b) Pd-Au alloys; (c) Pd-Rh alloys; (d) Pd-Ru alloys.

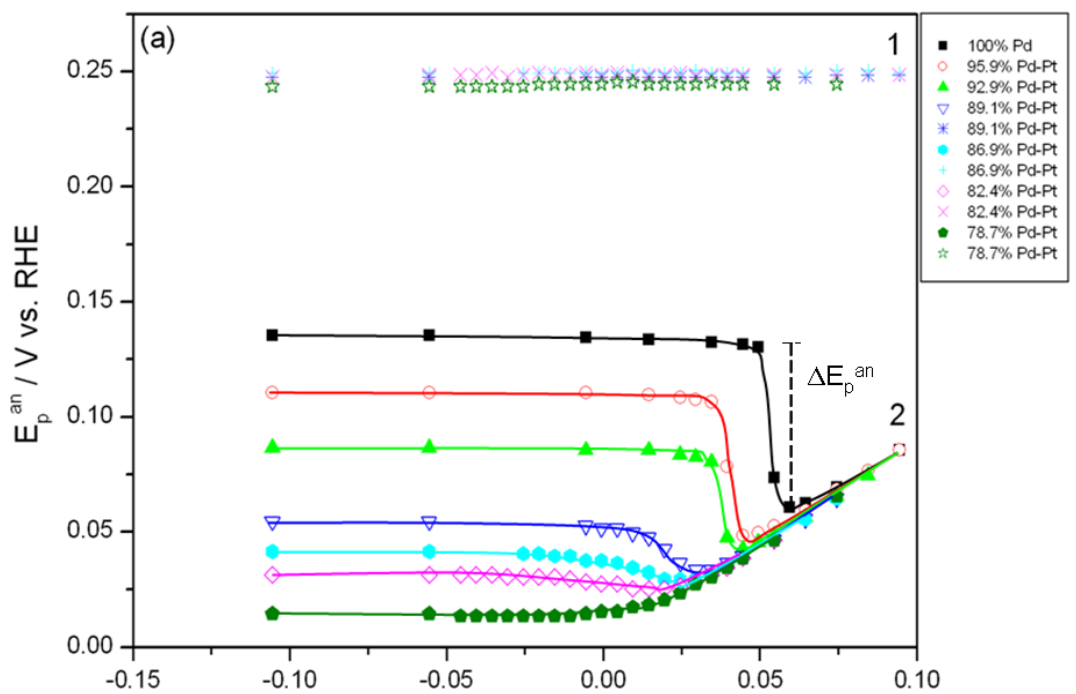

E/V vs. RHE

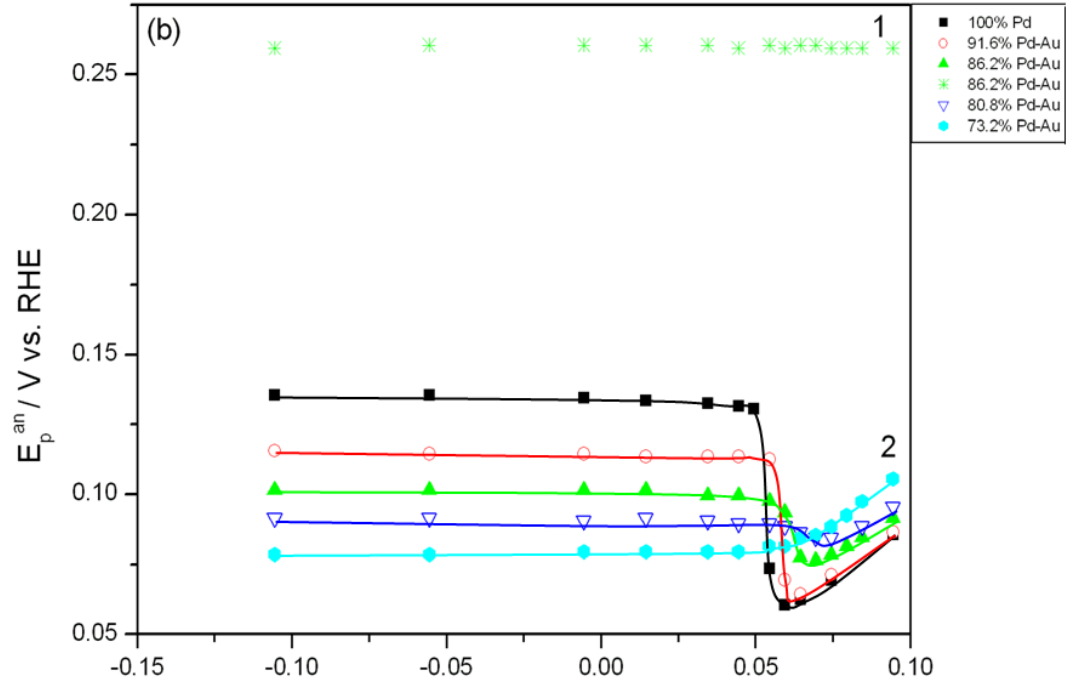

E / V vs. RHE

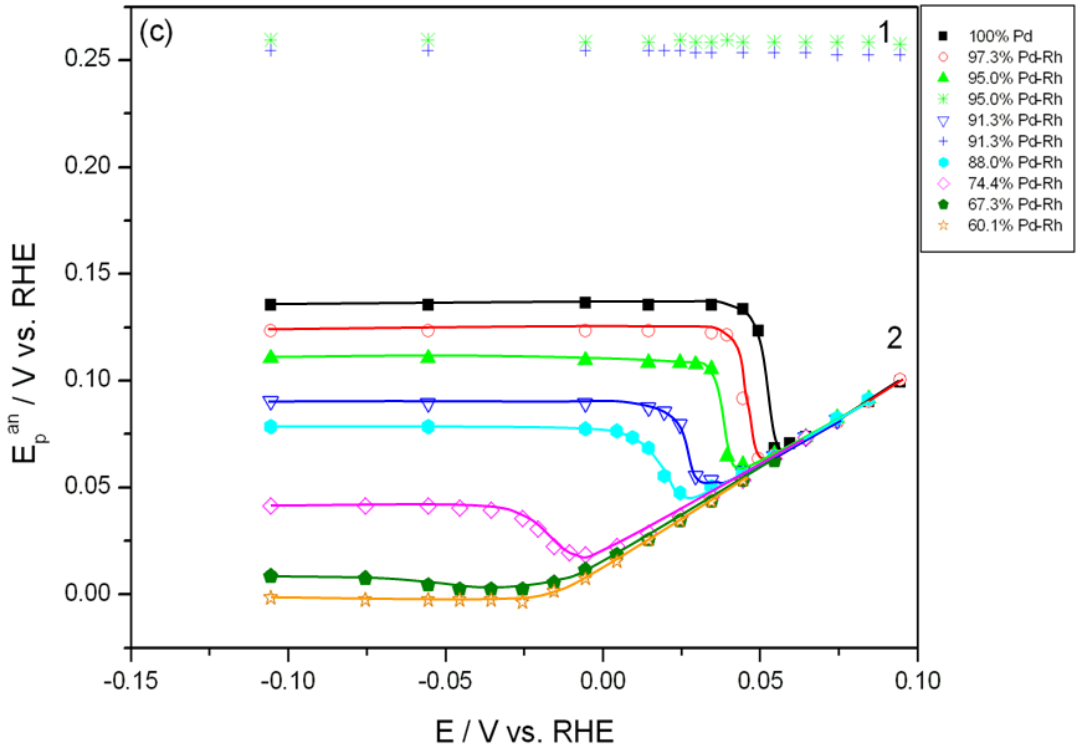


Figure 6. Cont.

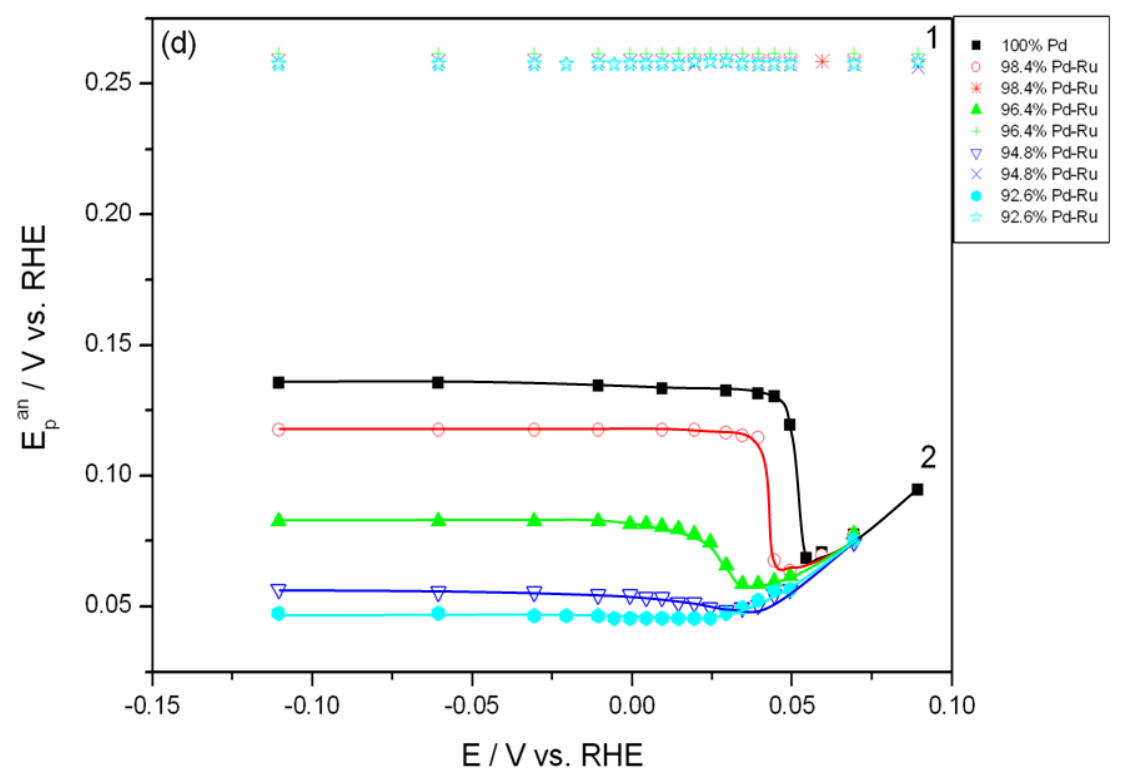

Figure 7 shows the effect of alloy bulk composition on the difference between the minimum value of the peak potential just before the phase transition and its final value at low electrosorption potentials $\left(\Delta \mathrm{E}_{\mathrm{p}}{ }^{\text {an }}\right.$, see Figure $\left.6 \mathrm{a}\right)$. For each kind of alloy this difference decreases with decreasing Pd bulk content from above $65 \mathrm{mV}$ for pure Pd to several $\mathrm{mV}$ for alloys with lower Pd content. This behavior can be explained by taking into account that for a certain alloy composition the miscibility gap in the alloy-hydrogen system disappears and only a single phase of absorbed hydrogen is present, i.e., no phase transition occurs. Indeed, the extrapolation of the potential $v s$. composition plot to zero gives an alloy composition that is very close to the limiting value characteristic for the single-phase system determined in independent chronoamperometric experiments [36,45]. The latter results are also in line with crystallographic data. Moreover, the potential difference correlates with the difference in H/M ratio at phase boundaries, i.e., $\beta_{\min }$ and $\alpha_{\max }$ (Figure 8), hysteresis (Figure 9) and the potential difference of anodic and cathodic peaks (Figure 10) as well as the difference in lattice constants for both phase boundaries taken from the literature [37,38] (Figure 11). Therefore, it can be concluded that from the analysis of the evolution of absorbed hydrogen oxidation peaks with alloy composition the important information on the properties of the phases of absorbed hydrogen can be extracted and this is connected with the width of the two-phase region in the Pd alloy-hydrogen system. These results again confirm the crucial role of the phase transition process on hydrogen sorption/desorption into/from thin Pd-based alloy layers. 
Figure 7. Influence of alloy bulk composition on the difference between minimum value of the potential of anodic peak 2 just before the phase transition and its final value at low electrosorption potentials $\left(\Delta \mathrm{E}_{\mathrm{p}}{ }^{\mathrm{an}}\right)$ : (a) for various alloys at $298 \mathrm{~K}$; (b) at various temperatures for Pd-Pt alloys.
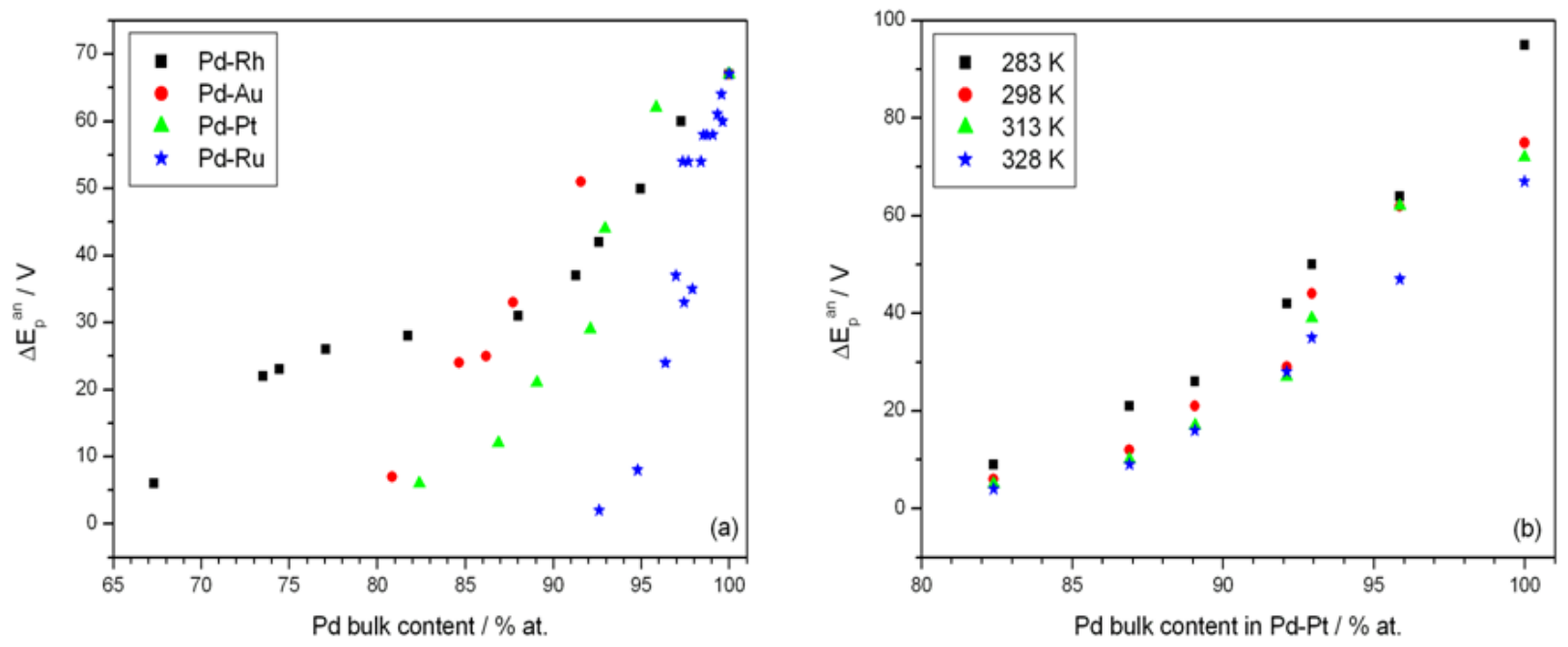

Figure 8. Correlation of the difference between minimum value of the potential of anodic peak 2 just before the phase transition and its final value at low electrosorption potentials $\left(\Delta \mathrm{E}_{\mathrm{p}}{ }^{\text {an }}\right)$ with the difference in $\mathrm{H} / \mathrm{M}$ ratio at phase boundaries: (a) for various alloys at 298 $\mathrm{K}$; (b) at various temperatures for Pd-Pt alloys.
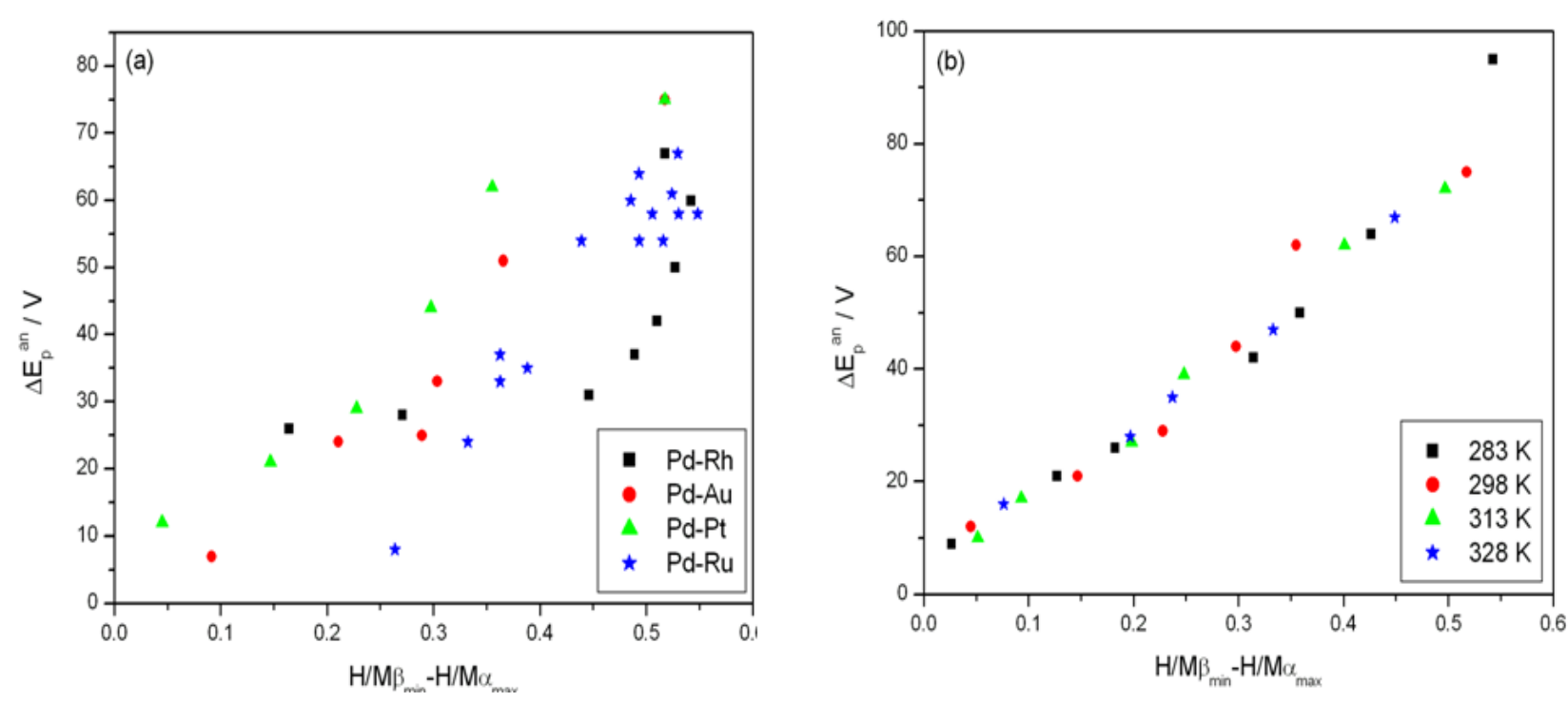
Figure 9. Correlation of the difference between minimum value of the potential of anodic peak 2 just before the phase transition and its final value at low electrosorption potentials $\left(\Delta \mathrm{E}_{\mathrm{p}}{ }^{\mathrm{an}}\right)$ with the absorption/desorption hysteresis: (a) for various alloys at $298 \mathrm{~K}$; (b) at various temperatures for Pd-Pt alloys.
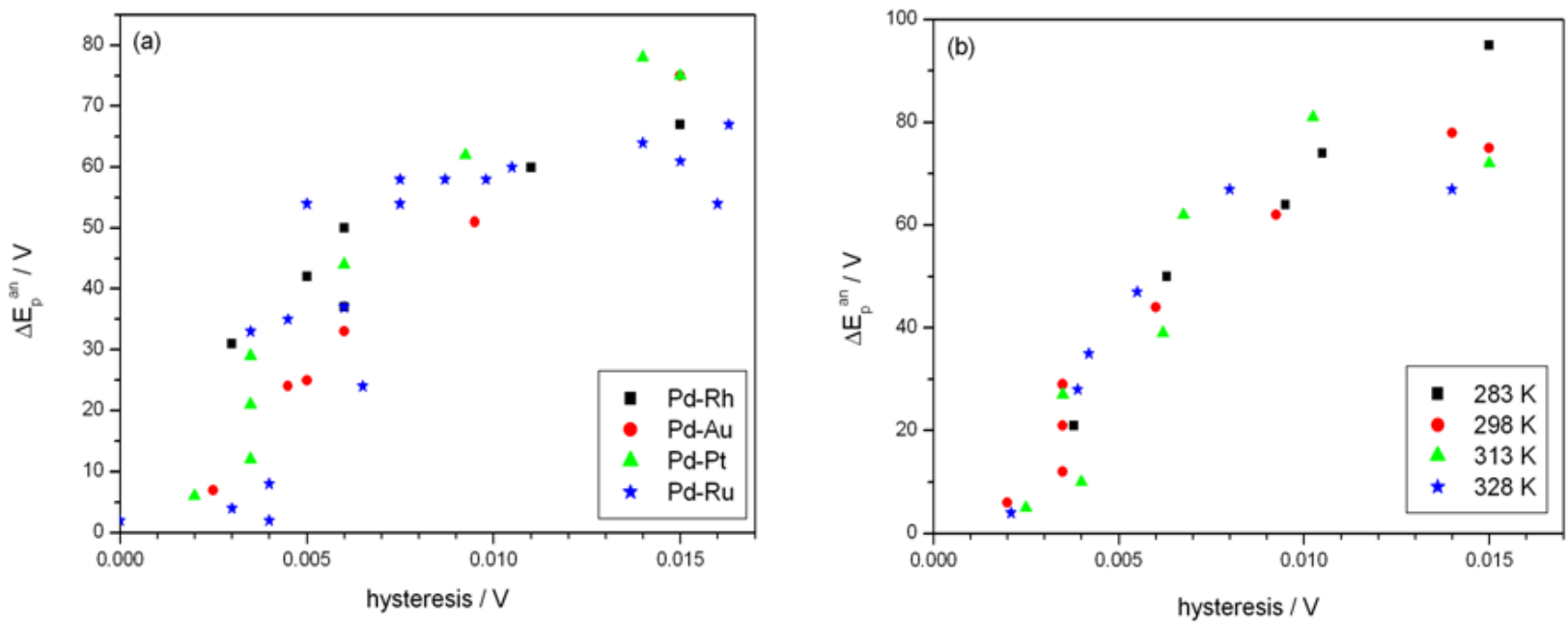

Figure 10. Correlation of the difference between minimum value of the potential of anodic peak 2 just before the phase transition and its final value at low electrosorption potentials $\left(\Delta \mathrm{E}_{\mathrm{p}}{ }^{\mathrm{an}}\right)$ with the potential difference of anodic and cathodic peaks 2: (a) for various alloys at $298 \mathrm{~K}$; (b) at various temperatures for Pd-Pt alloys.

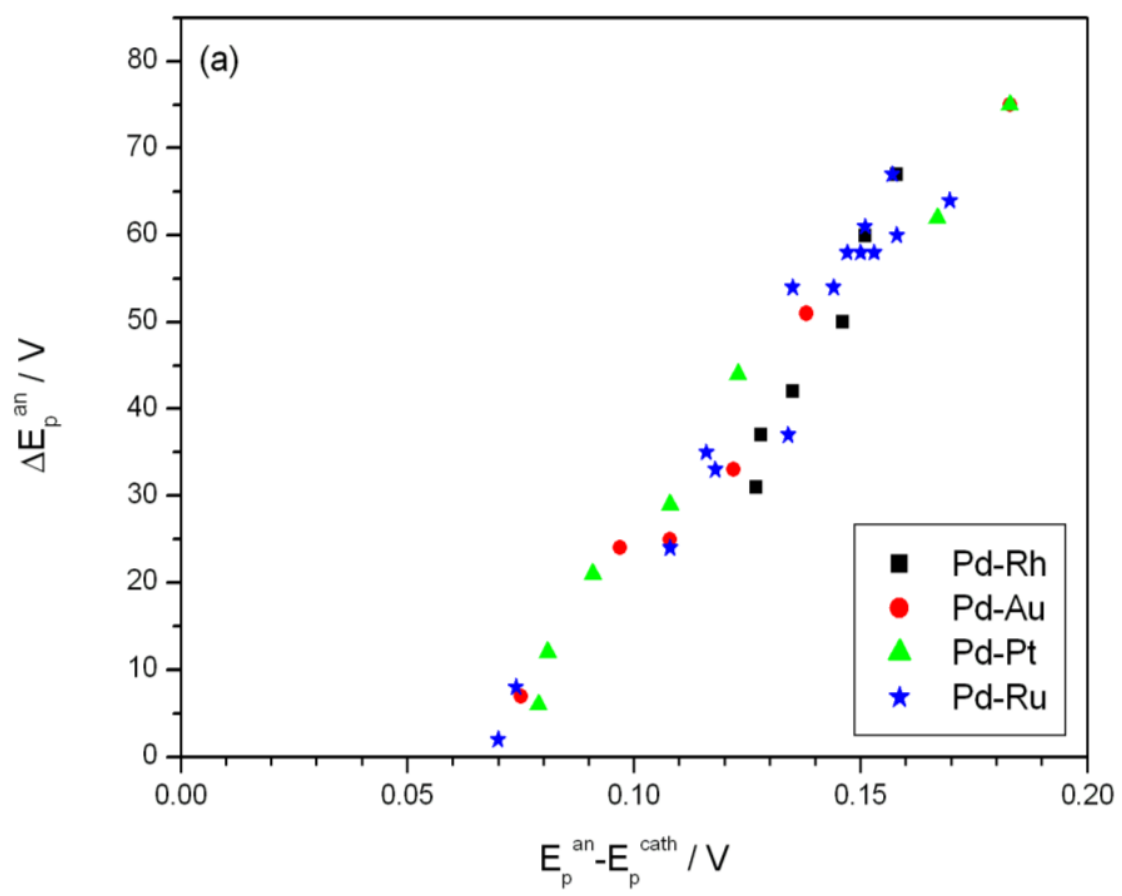


Figure 10. Cont.

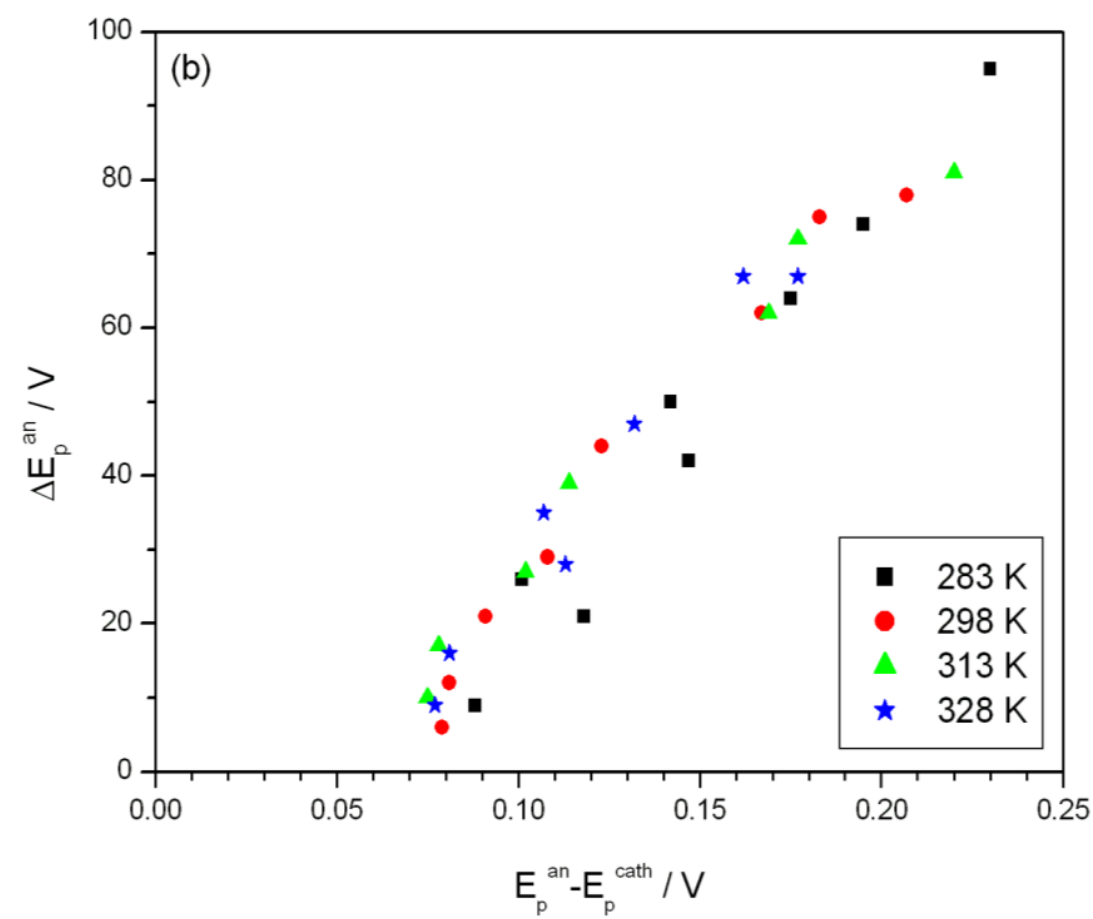

Figure 11. Correlation of the difference between minimum value of the potential of anodic peak 2 just before the phase transition and its final value at low electrosorption potentials $\left(\Delta \mathrm{E}_{\mathrm{p}}{ }^{\mathrm{an}}\right)$ with the difference in lattice constants for $\alpha$ - and $\beta$-phase boundaries taken from the literature $[37,38]$ for various alloys at $298 \mathrm{~K}$.

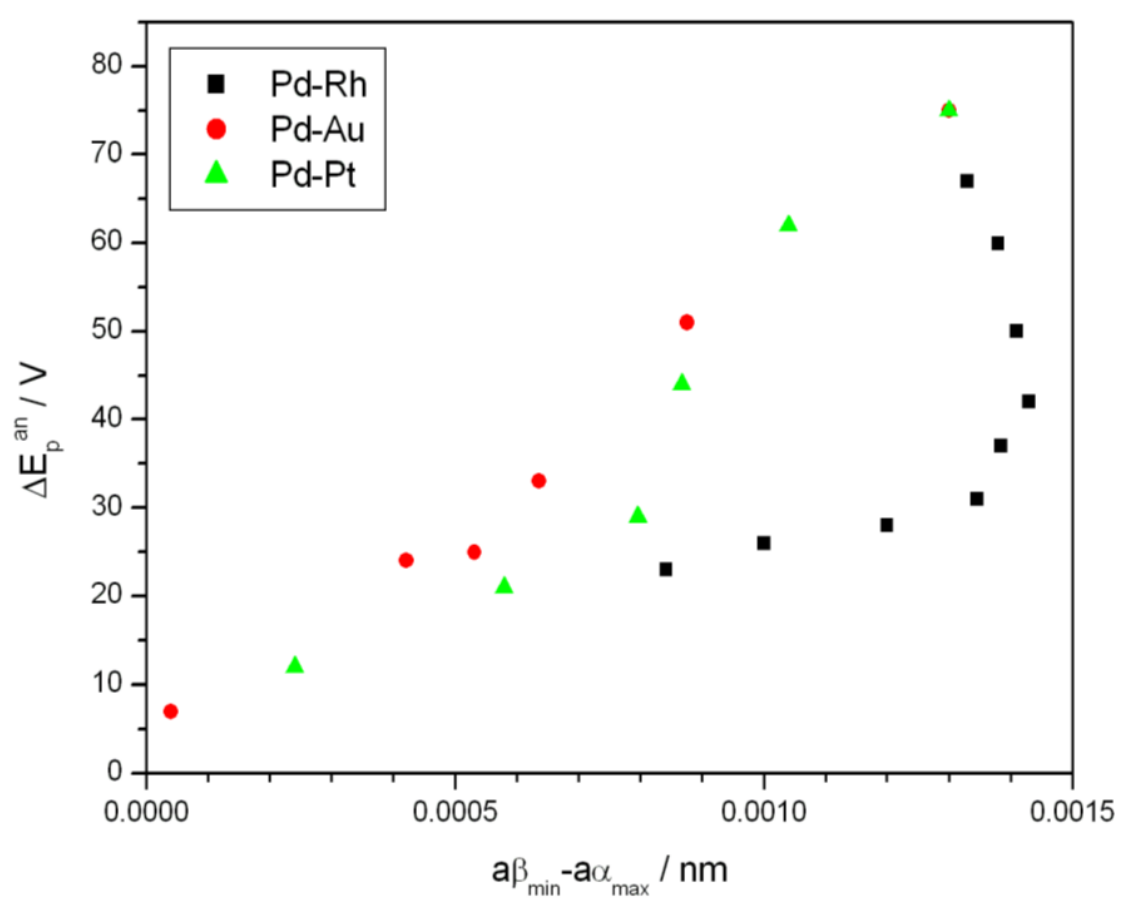

\section{Experimental Section}

All experiments were performed in $0.5 \mathrm{M} \mathrm{H}_{2} \mathrm{SO}_{4}$ solutions at temperature of $298 \mathrm{~K}$, and some of them additionally also in the range $283-328 \mathrm{~K}$. The temperature was controlled by a thermostat (Lauda 
RE 306, LAUDA DR. R. WOBSER GMBH \& CO. KG, Lauda-Königshofen, Germany). The solutions were prepared from analytical grade reagents and triply distilled water additionally purified in a Millipore system. Before the experiments the electrolyte was deoxygenated with an argon (99.999\%) stream for 20 min.; during the experiments the argon stream was directed above the solution level to protect from oxygenation from air. $\mathrm{A} \mathrm{Hg}\left|\mathrm{Hg}_{2} \mathrm{SO}_{4}\right| 0.5 \mathrm{M} \mathrm{H}_{2} \mathrm{SO}_{4}$ was used as the reference electrode. A Pt gauze was used as the auxiliary electrode. All potentials were recalculated with respect to the reversible hydrogen electrode (RHE) in the working solution according to procedures described earlier [36].

The working electrode was a gold wire $(99.99 \%, 0.5 \mathrm{~mm}$ diameter) covered with a thin alloy layer electrodeposited at a constant potential from baths prepared by mixing in various proportions aqueous solutions of $\mathrm{HAuCl}_{4}, \mathrm{H}_{2} \mathrm{PtCl}_{6}, \mathrm{RhCl}_{3}, \mathrm{RuCl}_{3}$ and $\mathrm{PdCl}_{2}$ with the addition of $\mathrm{HCl}$. Various alloy compositions were obtained by changing bath composition and deposition potential (see [36,45] for details). The alloy thickness was between 0.7 and $1.1 \mu \mathrm{m}$ and roughness factor was in the range 20-300. All alloy compositions are bulk compositions expressed in atomic percentages. The total amounts of the metals were analyzed by EDAX and atomic absorption or emission spectroscopy.

It was confirmed in hydrogen electrosorption studies [41] that the deposited alloys were homogeneous in bulk. It was found that the potential of $\alpha-\beta$ phase transition varied linearly with alloy bulk composition, which led to the conclusion that the hydrogen-absorbing phase was the only phase present in the system.

\section{Conclusions}

1. The analysis of the effect of electrosorption potential, scan rate and alloy bulk composition on hydrogen electrosorption signals recorded in cyclic voltammetric experiments for Pd and its alloys with $\mathrm{Pt}, \mathrm{Au}, \mathrm{Rh}$ and $\mathrm{Ru}$ leads to the conclusion that the signals placed in the potential range $0.23-0.32 \mathrm{~V}$ can be attributed mainly to hydrogen adsorption with a small contribution from hydrogen absorption in the $\alpha$-phase, while the signals placed below $0.15 \mathrm{~V}$ originate mainly from hydrogen absorption in the $\alpha$ - or $\beta$-phase (for alloys sufficiently rich in $\mathrm{Pd}$ ) as well as from hydrogen adsorption.

2. It was observed that the height and potential of the former signals are weakly dependent on the electrosorption potential and alloy composition, with peak currents proportional to scan rate of the power of 0.9-1.0. In contrast, the latter signals are much more influenced by electrosorption potential and alloy composition, with peak currents proportional to scan rate of the power of $0.55-0.75$.

3. The experimental results are in a good qualitative agreement with a model established by Zhang et al. [33] assuming the phase transition as the rate-determining step in the overall process of hydrogen absorption/desorption into/from thin Pd-base electrodes. In the course of the dependence of the hydrogen oxidation peak potential on the electrosorption potential and alloy bulk composition, information is contained on limiting $\mathrm{Pd}$ bulk content, below which the $\beta$-phase in the alloy-hydrogen systems is not formed.

4. It was found that the way of evolution of hydrogen oxidation peak potential with electrosorption potential is dependent on the difference in $\mathrm{H} / \mathrm{M}$ ratio at the $\alpha, \beta$ phase boundaries, hysteresis, the potential difference of anodic and cathodic peaks and the difference in lattice constants for both phases. 


\section{Acknowledgments}

This work was financially supported by NCN (National Center of Science), grant No. DEC-2011/01/B/ST4/00442.

\section{Conflicts of Interest}

The authors declare no conflict of interest.

\section{References}

1. Schlapbach, L.; Züttel, A. Hydrogen-storage materials for mobile applications. Nature 2001, 414, 353-358.

2. Kleperis, J.; Wójcik, G.; Czerwiński, A.; Skowroński, J.; Kopczyk, M.; Bełtowska-Brzezińska, M. Electrochemical behavior of metal hydrides. J. Solid State Electrochem. 2001, 5, 229-249.

3. Kijeński, J. Why hydrogen? Przem. Chem. 2005, 84, 799-807.

4. Crabtree, G.W.; Dresselhaus, M.S.; Buchanan, M.V. The hydrogen economy. Phys. Today 2004, 57, 39-44.

5. Grochala, W.; Edwards, P.P. Thermal decomposition of the non-interstitial hydrides for the storage and production of hydrogen. Chem. Rev. 2004, 104, 1283-1315.

6. Züttel, A.A. Hydrogen storage methods. Naturwissenschaften 2004, 91, 157-172.

7. Lewis, F.A. The Palladium/Hydrogen System; Academic Press: London, UK, 1967.

8. Wicke, E.; Brodowsky, H.; Züchner, H. Hydrogen in Metals II. Topics in Applied Physics; Alefeld, G., Völkl, J., Eds.; Springer-Verlag: Berlin, Germany, 1978; Volume 29, pp. 73-155.

9. Oates, W.A.; Flanagan, T.B. The solubility of hydrogen in transition metals and their alloys. Prog. Solid State Chem. 1981, 13, 193-283.

10. Flanagan, T.B.; Oates, W.A. The Palladium-hydrogen system. Annu. Rev. Mater. Sci. 1991, 21, 269-304.

11. McLellan, R.B.; Harkins, C.G. Hydrogen interactions with metals. Mater. Sci. Eng. 1975, 18, 5-35.

12. Jerkiewicz, G. Electrochemical hydrogen adsorption and absorption. Part 1: Under-potential deposition of hydrogen. Electrocatalysis 2010, 1, 179-199.

13. Jerkiewicz, G. Hydrogen sorption at/in electrodes. Prog. Surf. Sci. 1998, 57, 137-186.

14. Grdeń, M.; Łukaszewski, M.; Jerkiwicz, G.; Czerwiński, A. Electrochemical behaviour of palladium electrode: Oxidation, electrodissolution and ionic adsorption. Electrochim. Acta 2008, 53, 7583-7598.

15. Flanagan, T.B.; Sakamoto, Y. Hydrogen in disordered and ordered palladium alloys. Int. J. Hydrog. Energy 1994, 19, 151-159.

16. Sakamoto, Y.; Chen, F.L.; Ura, M.; Flanagan, T.B.; Thermodynamic properties for solution of hydrogen in palladium-based binary alloys. Ber. Bunsenges. Phys. Chem. 1995, 99, 807-820.

17. Lasia, A.; Grégoire, D. General model of electrochemical hydrogen absorption into metals. J. Electrochem. Soc. 1995, 142, 3393-3399.

18. Duncan, H.; Lasia, A. Mechanism of hydrogen adsorption/absorption at thin Pd layers on $\mathrm{Au}(111)$. Electrochim. Acta 2007, 52, 6195-6205. 
19. Łukaszewski, M.; Czerwiński, A. Limited volume electrodes as a tool for electrochemical studies on hydrogen absorption in palladium and its alloys. J. Solid State Electrochem. 2011, 15, 2489-2522.

20. Grdeń, M.; Piaścik, A.; Koczorowski, Z.; Czerwiński, A. Hydrogen electrosorption in Pd-Pt alloys. J. Electroanal. Chem. 2002, 532, 35-42.

21. Woods, R. Chemisorption at Electrodes. In Electroanalytical Chemistry; Bard, A.J., Ed.; Marcel Dekker: New York, NY, USA, 1976; Volume 9, pp. 1-162.

22. Gabrielli, C.; Grand, P.P.; Lasia, A.; Perrot, H. Investigation of hydrogen adsorption and absorption in palladium thin films. II. Cyclic voltammetry. J. Electrochem. Soc. 2004, 151, 1937-1942.

23. Duncan, H.; Lasia, A. Separation of hydrogen adsorption and absorption on Pd thin films. Electrochim. Acta 2008, 53, 6845-6850.

24. Żurowski, A.; Łukaszewski, M.; Czerwiński, A. Electrosorption of hydrogen into palladium-rhodium alloys. Part 2: Pd-rich electrodes of various thickness. Electrochim. Acta 2008, 53, 7812-7816.

25. Duncan, H.; Lasia, A. Hydrogen adsorption/absorption on $\mathrm{Pd} / \mathrm{Pt}(111)$ multilayers. J. Electroanal. Chem. 2008, 621, 62-68.

26. Jurczakowski, R.; Łosiewicz, B.; Lasia, A. Kinetic and thermodynamic parameters of hydrogen sorption in Pd, Pd-Pt and on Pt. ECS Trans. 2007, 2, 11-19.

27. Słojewski, M.; Kowalska, J.; Jurczakowski, R. Influence of phosphorus content on hydrogen sorption in Pd-P thin layers obtained by electroless deposition. J. Phys. Chem. C 2009, 113, 3707-3712.

28. Bartlett, P.N.; Marwan, J. The effect of surface species on the rate of $\mathrm{H}$ sorption into nanostructured Pd. Phys. Chem. Chem. Phys. 2004, 6, 2895-2898.

29. Martin, M.H.; Lasia, A. Hydrogen sorption in Pd monolayers in alkaline solution. Electrochim. Acta 2009, 54, 5292-5299.

30. Grdeń, M.; Paruszewska, A.; Czerwiński, A. Electrosorption of carbon dioxide on Pd-Pt alloys. J. Electroanal. Chem. 2001, 502, 91-99.

31. Łukaszewski, M.; Grdeń, M.; Czerwiński, A. Influence of adsorbed carbon dioxide on hydrogen electrosorption in palladium-platinum-rhodium alloys. Electrochim. Acta 2004, 49, 3161-3167.

32. Podlovchenko, B.I.; Kolyadko, E.A.; Lu, S. Specific features of hydrogen sorption by palladium dispersed forms at $\alpha$-phase potentials. J. Electroanal. Chem. 1995, 399, 21-27.

33. Zhang, W.S.; Zhang, X.W.; Zhao, X.G. Voltammograms of thin layer Pd/H(D) electrodes in the coexistence of $\alpha$ and $\beta$ phases. J. Electroanal. Chem. 1998, 458, 107-112.

34. Łukaszewski, M.; Grdeń, M.; Czerwiński, A. Comparative study on hydrogen electrosorption in palladium and palladium-noble metal alloys. J. New Mater. Electrochem. Syst. 2006, 9, 409-417.

35. Guerin, S.; Attard, G.S. Electrochemcial behavior of electrodeposited nanostructured palladium+platinum films in $2 \mathrm{M} \mathrm{H}_{2} \mathrm{SO}_{4}$. Electrochem. Commun. 2001, 3, 544-548.

36. Lukaszewski, M.; Hubkowska, K.; Czerwiński, A. Comparative study on the influence of temperature, electrode potential and alloy bulk composition on hydrogen electrosorption into Pd-Pt and Pd-Au alloys. J. Electroanal. Chem. 2011, 651, 131-142.

37. Sakamoto, Y.; Yuwasa, K.; Hirayama, K. X-ray investigation of the absorption of hydrogen by several palladium and nickel solid solution alloys. J. Less Common Met. 1982, 88, 115-124. 
38. Sakamoto, Y.; Baba, K.; Flanagan, T.B. The effect of alloying of palladium on the hydrogen-palladium miscibility gap. Z. Phys. Chem. Neue Folge 1988, 158, 223-235.

39. Wicke, E.; Frölich, K. Electronic and elastic effect in the phase diagrams of binary Pd alloy hydrides. Z. Phys. Chem. Neue Folge 1989, 163, 35-40.

40. Trasatti, S. Work function, electronegativity, and electrochemical behavior of metals. III. Electrolytic hydrogen evolution in acid solutions. J. Electroanal. Chem. 1972, 39, 163-184.

41. Łukaszewski, M.; Hubkowska, K.; Czerwiński, A. Electrochemical absorption and oxidation of hydrogen into/on palladium alloys with platinum, gold and rhodium. Phys. Chem. Chem. Phys. 2010, 12, 14567-14572.

42. Millet, P.; Srour, M.; Faure, R.; Durand, R. A study of hydrogen absorption and desorption reactions in palladium electrodes using the potential step method. Electrochem. Commun. 2001, 3, 478-482.

43. Lee, J.W.; Pyun, S.I. Anomalous behaviour of hydrogen extraction from hydride-forming metals and alloys under impermeable boundary conditions. Electrochim. Acta 2005, 50, 1777-1805.

44. Czerwinski, A.; Marassi, R.; Zamponi, S. The absorption of hydrogen and deuterium in thin palladium electrodes. Part I. Acidic solutions. J. Electroanal. Chem. Interfacial Chem. 1991, 316, 211-221.

45. Koss, U.; Łukaszewski, M.; Hubkowska, K.; Czerwiński, A. Influence of Rh additive on hydrogen electrosorption in Pd-rich Pd-Rh alloys. J. Solid State Electrochem. 2011, 15, 2477-2487.

(C) 2013 by the authors; licensee MDPI, Basel, Switzerland. This article is an open access article distributed under the terms and conditions of the Creative Commons Attribution license (http://creativecommons.org/licenses/by/3.0/). 